Article

\title{
Ru Nanoparticles Embedded in Cubic Mesoporous Silica SBA-1 as Highly Efficient Catalysts for Hydrogen Generation from Ammonia Borane
}

\author{
Juti Rani Deka ${ }^{1}\left(\right.$, Diganta Saikia ${ }^{2} \oplus$, Kuo-Shu Hsia ${ }^{2}$, Hsien-Ming Kao ${ }^{2, *} \mathbb{D}$, Yung-Chin Yang ${ }^{1, *}$ \\ and Ching-Shiun Chen ${ }^{3,4, *(1)}$ \\ 1 Institute of Materials Science and Engineering, National Taipei University of Technology, Taipei 106, Taiwan; \\ juti.deka@gmail.com \\ 2 Department of Chemistry, National Central University, Chung-Li 32054, Taiwan; digantas@gmail.com (D.S.); \\ genuine3344@gmail.com (K.-S.H.) \\ 3 Center for General Education, Chang Gung University, Taoyuan City 33302, Taiwan \\ 4 Department of Pathology, Chang Gung Memorial Hospital, Taoyuan City 33302, Taiwan \\ * Correspondence: hmkao@cc.ncu.edu.tw (H.-M.K.); ycyang@ntut.edu.tw (Y.-C.Y.); \\ cschen@mail.cgu.edu.tw (C.-S.C.)
}

Received: 3 December 2019; Accepted: 24 February 2020; Published: 26 February 2020

\begin{abstract}
Cubic mesoporous silica SBA-1 functionalized with carboxylic acid (-COOH), namely S1B-C10, is used as a support to fabricate and confine Ru nanoparticles (NPs). The uniformly dispersed organic functional groups in SBA-1 are beneficial in attracting Ru cations, and as a result, homogenously distributed small sized Ru NPs are formed within the mesopores. The prepared $\mathrm{Ru} @ S 1 B-C 10$ is utilized as a catalyst for $\mathrm{H}_{2}$ generation from the hydrolysis of ammonia borane (AB). The Ru@S1B-C10 catalyst demonstrates high catalytic activity for $\mathrm{H}_{2}$ generation $\left(202 \mathrm{~mol} \mathrm{H}_{2}\right.$ $\left.\mathrm{mol}_{\mathrm{Ru}} \mathrm{min}^{-1}\right)$ and lower activation energy $\left(24.13 \mathrm{~kJ} \mathrm{~mol}^{-1}\right)$ due to the small sized Ru NPs with high dispersion and the support's interconnected mesoporous structure. The nanosized Ru particles provide abundant active sites for the catalytic reaction to take place, while the interconnected porous support facilitates homogenous transference and easy dispersal of AB molecules to the active sites. The catalyst demonstrates good recycle ability since the accumulation and leaking of NPs throughout catalysis can be effectively prevented by the support.
\end{abstract}

Keywords: mesoporous silica; carboxylic acid; Ru; ammonia borane; hydrolysis

\section{Introduction}

Hydrogen is considered as one of the cleanest fuels with high chemical energy, and thus receives tremendous attention as a potential renewable energy carrier for future energy applications. However, safety and efficient storage of hydrogen is a great challenge for its widespread utilization. Amongst the various physical and chemical approaches, such as adsorption, compression, and liquefaction, interests have been growing in hydrogen generation from chemical hydrogen storage materials [1-4] as they are convenient to carry safely and can be stored easily. A variety of hydrogen storage materials, such as sodium borohydride $\left(\mathrm{NaBH}_{4}\right)[5,6]$, ammonia borane $\left(\mathrm{NH}_{3} \mathrm{BH}_{3}, \mathrm{AB}\right)[7,8]$, hydrazine $\left(\mathrm{N}_{2} \mathrm{H}_{4} \cdot \mathrm{H}_{2} \mathrm{O}\right)[9]$, and formic acid $(\mathrm{HCOOH})[10]$, have been used for hydrogen generation. Ammonia borane (AB) has received particular interest among the hydrogen storage materials because of its high amount of hydrogen (19.6 wt \%), low molecular weight (30.87 $\left.\mathrm{g} \mathrm{mol}^{-1}\right)$, non-toxic character, and high stableness in neutral aqueous solution at room temperature [1,11]. Hydrogen can be released from AB through thermal dehydrogenation in the solid state [12,13], and hydrolysis [14-16] or methanolysis [17-19] in solution. Although AB can release hydrogen through thermal dehydrogenation in the solid state, it 
generally requires higher temperatures $\left(>80^{\circ} \mathrm{C}\right)$ to release more hydrogen and presents a relatively low hydrogen generation rate $[20,21]$. However, an equivalent amount of hydrogen can be generated from the hydrolysis of $\mathrm{AB}$ at room temperature using an appropriate catalyst. The reaction takes place is expressed as $[22,23]$

$$
\mathrm{NH}_{3} \mathrm{BH}_{3}+2 \mathrm{H}_{2} \mathrm{O} \rightarrow \mathrm{NH}_{4}^{+}+\mathrm{BO}^{2-}+3 \mathrm{H}_{2}
$$

The development of a proper catalyst with high catalytic performance for hydrogen release by means of $\mathrm{AB}$ hydrolysis has prompted significant research attention over the past decades. Noble metals, such as Pt [24], Pd [25], Ag [26], and Ru [27-29] based catalysts, can promptly generate hydrogen from $\mathrm{AB}$ and hence have been touted as greatly effective catalysts. However, the scarcity of resources and high cost of noble metals are the great challenges for their extensive application. This drawback of the noble-metal-based catalysts could be overcome by reducing the particle size to the nanometer dimension to achieve a high surface area and more numbers of active sites. However, small sized metal nanoparticles (NPs) with high surface energy have the inherent tendency to agglomerate and as a result the catalytic activity is reduced greatly. The use of proper support is the most effective approach to prevent the agglomeration problem of the metal NPs. Various materials with high surface areas, such as graphene [30], active carbon [31], carbon nanotubes [32], and mesoporous silica [33,34], have been employed as supports for immobilization of metal NPs in order to obtain homogenous dispersion of the metal NPs in the support. Mesoporous silicas, such as SBA-15, MCM-41, FDU-12, and SBA-16, have been widely used as the supports for the incorporation of the metal NPs due to their large surface areas, pore volumes, and homogenous pore structures [35-40]. In particular, 3D cubic mesoporous silicas like FDU-12, SBA-16, and SBA-1 are of great interest as the supports for the entrapment of the metallic NPs, since their interpenetrating mesoporous networks are resilient to pore blocking, and hence the catalysts can provide more active sites for the catalytic reactions [41,42]. In addition, the use of 3D mesoporous support prevents agglomeration of metal NPs and offers more open spaces for the faster diffusion of the reactants. The product molecules can exit easily through these interconnected mesopores as well. Unfortunately, agglomeration of metal NPs still takes place because of the poor electrostatic interaction between the pure mesoporous silica and the metal NPs that decrease the performance of the catalyst. The surface of the mesoporous silicas is hence altered by integrating organic functional groups, such as carboxylic acid (-COOH) [43], amino $\left(\mathrm{NH}_{2}\right)$ [44], and thiol $\left(\mathrm{SO}_{3}\right)$ [45] etc., to confine the metal NPs firmly within the support.

In this work, 3D cage-type mesoporous silica SBA-1 functionalized with - $\mathrm{COOH}$ groups is employed as the support to confine Ru NPs. The prepared materials are utilized as the catalysts for the hydrogen release from AB through hydrolysis. Mesoporous silica SBA-1 possesses cage-type mesopores, which are connected to each other by small entrance windows. The use of SBA-1 as the support is expected to govern the metal NPs growth effectively and precludes the NPs from agglomeration. The $-\mathrm{COOH}$ functional groups are introduced into SBA-1 via co-condensation of tetraethyl orthosilicate (TEOS) and carboxyethylsilanetriol sodium salt (CES) in the presence of poly(acrylic acid) (PAA) and hexadecylpyridinium chloride (CPC). The Ru NPs with a very small size can be incorporated into the mesopores of SBA-1 by the chemical reduction approach. The co-condensation synthesis route has an advantage since it can distribute the - $\mathrm{COOH}$ groups within the mesopores uniformly, which eventually help the Ru NPs to be dispersed homogenously within the support. Ru NPs encapsulated in the - $\mathrm{COOH}$ functionalized SBA-1 display high catalytic performance for hydrogen generation from hydrolysis of AB. The leaching of Ru NPs can also be overcome as the -COOH groups can confine the Ru NPs firmly because of the strong electrostatic attractive force between the carboxylate and Ru cations. The presence of - $\mathrm{COOH}$ groups within the mesopores is helpful as it can control the size of the metal NPs and reduce leaching during recycling, which in the end increased the stability of the catalyst.

\section{Results}

To explore the feasibility of the prepared S1B-C0 and S1B-C10 as the supports for the encapsulation of the Ru NPs, the microstructural and the textural properties of the template extracted S1B-C0 and 
S1B-C10 were studied. The small angle X-ray diffraction SXRD patterns of S1B-C0 and S1B-C10 shown in Figure 1A revealed three well defined peaks that could be credited to the (200), (210), and (211) diffractions of SBA- 1 with $P m \overline{3} n$ symmetry. Although the intensity of the most extrusive peak decreased slightly on inclusion of - $\mathrm{COOH}$ organic groups, similar XRD patterns of S1B-C10 with those of S1B-C0 indicated that the mesoporosity of S1B-C10 remained intact. The $\mathrm{N}_{2}$ adsorption-desorption isotherms also showed similar type IV isotherms with two adsorption steps at $\mathrm{P} / \mathrm{P}_{0}$ of $0.3-0.5$ and $0.75-0.95$ in both the materials S1B-C0 and S1B-C10 as seen in Figure 1B, which further indicated that the mesostructural ordering has not significantly degraded in S1B-C10 on inclusion of the functional organic groups. The surface area and pore volume of S1B-C10 were $850 \mathrm{~m}^{2} \mathrm{~g}^{-1}$ and $1.84 \mathrm{~cm}^{3} \mathrm{~g}^{-1}$, respectively, slighter larger than those of S1B-C0 $\left(832 \mathrm{~m}^{2} \mathrm{~g}^{-1}\right.$ and $\left.1.23 \mathrm{~cm}^{3} \mathrm{~g}^{-1}\right)$, which could be ascribed to the intrinsic correlations between the cationic surfactant $\mathrm{CPC}$ and $\mathrm{Na}^{+}$that exists in carboxyethylsilanetriol (CES). The interrelation facilitated the co-assembling of the inorganic constituents with the template along with the cross-linking of the silica framework. The presence of mesopores in both S1B-C0 and S1B-C10 were also realized from the TEM images presented in Figure 2A. It was observed that both the materials exhibited highly ordered cage-type mesopores in 3D arrays, which is typical of cubic mesopores with $P m \overline{3} n$ symmetry. The pore sizes were measured to be around $3 \mathrm{~nm}$, which was persistent with the pore size estimated from the $\mathrm{N}_{2}$ adsorption-desorption measurements. The FTIR spectra of both S1B-C0 and S1B-C10 presented in Figure 2B showed highly intense bands at 948 and $3450 \mathrm{~cm}^{-1}$ for $\mathrm{Si}-\mathrm{OH}$ groups and at $1076 \mathrm{~cm}^{-1}$ for the Si-O-Si linkage. The FTIR spectra also showed a peak of high intensity at $1636 \mathrm{~cm}^{-1}$, which could be attributed to the bending mode of $\mathrm{H}_{2} \mathrm{O}$. An extra band at $1720 \mathrm{~cm}^{-1}$, characteristic of - $\mathrm{COOH}$ organic functional groups, was also observed in the FTIR spectrum of S1B-C10, as shown in Figure 2Bb, indicating the successful incorporation of the -COOH groups into the mesoporous silica framework. The incorporation of the $-\mathrm{COOH}$ functional groups were further substantiated by the solid state NMR spectroscopy. Three peaks at the chemical shifts of 7,27, and $178 \mathrm{ppm}$ were observed in the ${ }^{13} \mathrm{C}$ cross polarization magic angle spinning (CPMAS) NMR spectrum of S1B-C10 shown in Figure 3A, which could be ascribed to the $\mathrm{C} 1, \mathrm{C} 2$, and $\mathrm{C} 3$ carbon atoms of the silica framework (Si-O-Si-C(1)-C(2)-C(3)OOH) due to the incorporated - $\mathrm{COOH}$ moiety.
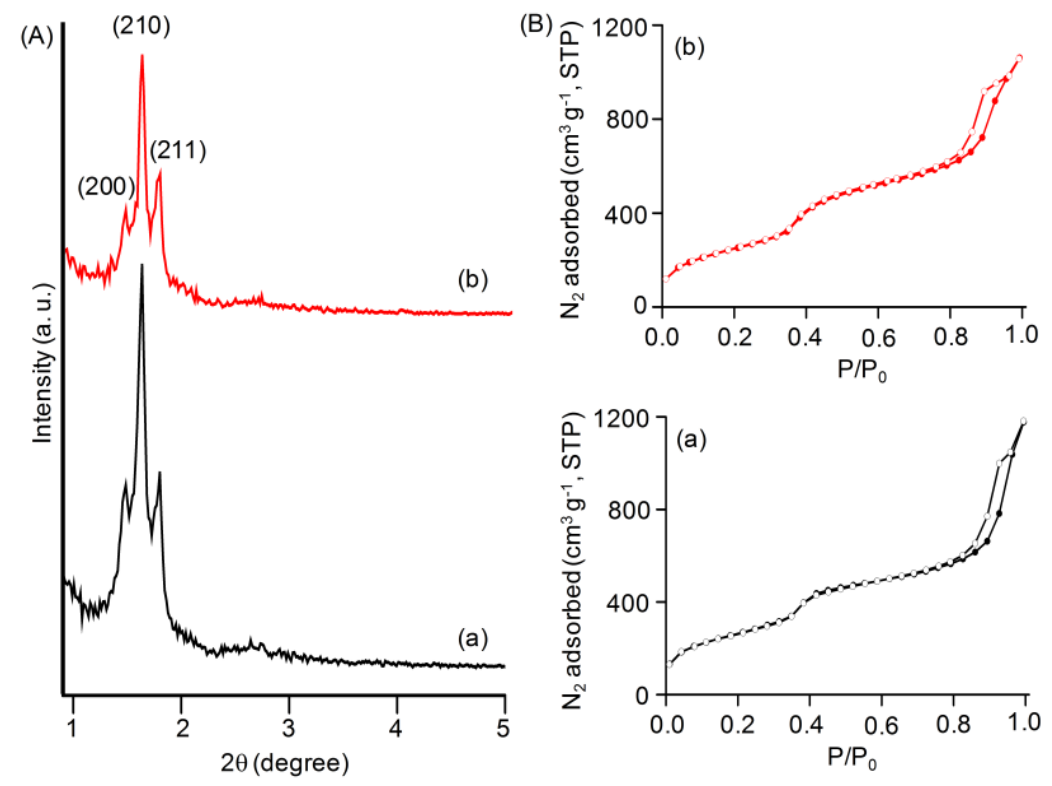

Figure 1. Small angle XRD patterns (A) and $\mathrm{N}_{2}$ sorption isotherms (B) of (a) S1B-C0 and (b) S1B-C10. 

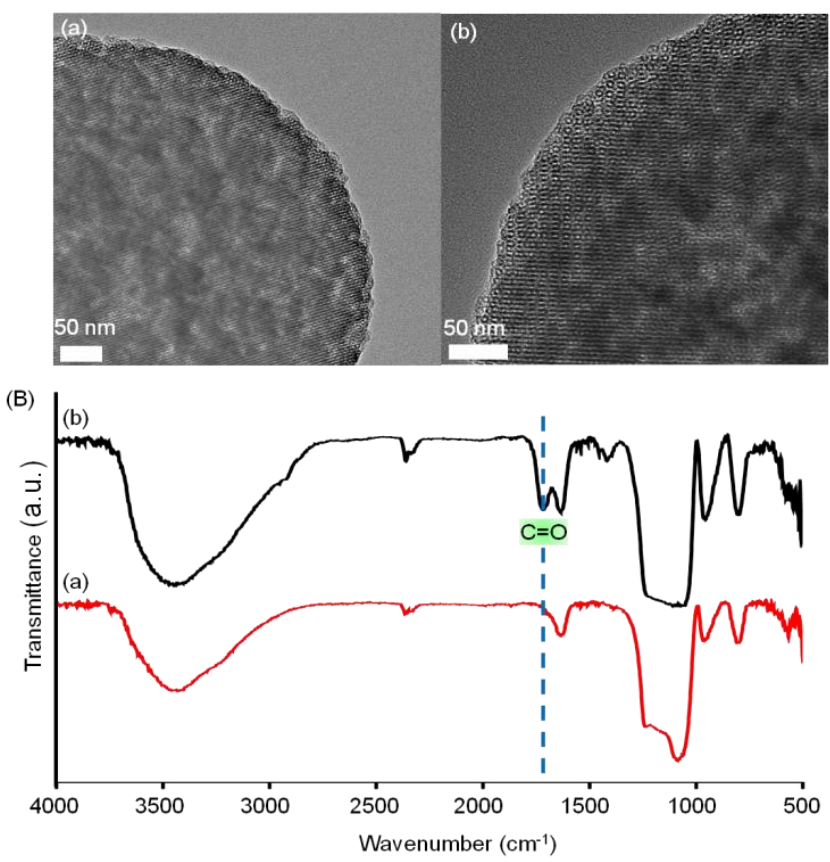

Figure 2. TEM images (A) and FTIR spectra (B) of (a) S1B-C0 and (b) S1B-C10.

(A)

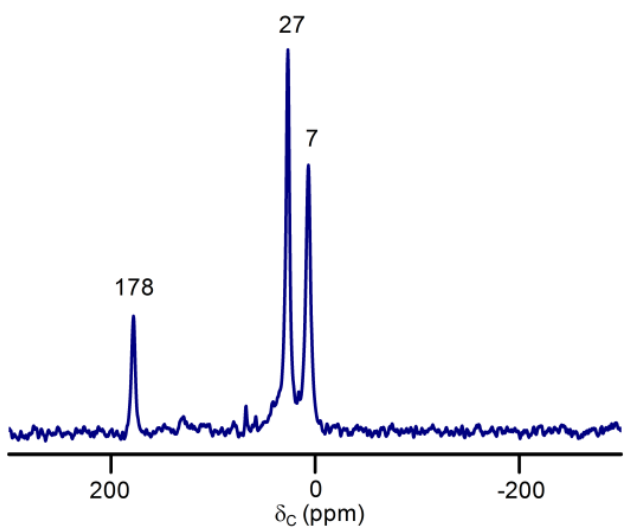

(B)

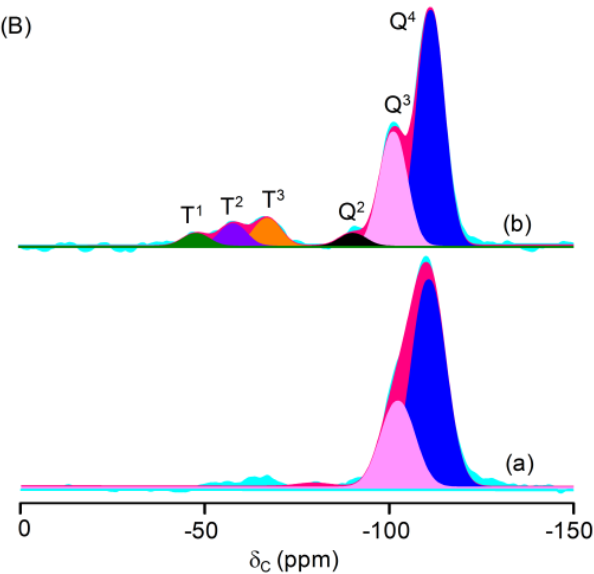

Figure $3 .{ }^{13} \mathrm{C}$ cross polarization magic angle spinning (CPMAS) NMR spectrum of S1B-C10 (A), and ${ }^{29}$ Si MAS NMR spectra (B) of (a) S1B-C0 and (b) S1B-C10.

A ${ }^{29} \mathrm{Si}$ MAS NMR study was carried out on S1B-C0 and S1B-C10 to determine the actual -COOH functionalization level and the results are presented in Figure 3B. The presence of both $Q$ and $T$ species were noticed in the ${ }^{29} \mathrm{Si}$ MAS NMR spectrum of S1B-C10, as shown in Figure 3B-b, in contrast to only $Q$ species in S1B-C0, as shown in Figure 3Ba. The $Q$ species were due to the condensation of TEOS, whereas the $T$ species were due to the incorporation of carboxylic acid moiety from CES. The organic functionalization level was determined from the deconvulation of the ${ }^{29}$ Si MAS NMR spectra and estimated to be around 10\%. The zeta potential measurements shown in Figure S1 demonstrated that the surface of S1B-C10 was relatively more negatively charged compared to S1B-C0 within the studied $\mathrm{pH}$ range of 3 to 9 , that could be accredited to the partial dissociation of the - $\mathrm{COOH}$ groups. This also propagated the inclusion of organic - $\mathrm{COOH}$ groups for the case of $\mathrm{S1B}-\mathrm{C} 10$. The analysis of microstructural, surface, and textural properties revealed that the prepared materials could act as suitable supports for the immobilization of metal NPs. The prepared mesoporous silica S1B-C0 and S1B-C10 were used as the supports to immobilize Ru NPs with various loadings. The small angle XRD patterns of the Ru NPs encapsulated in S1B-C0 and S1B-C10 depicted in Figure 4 demonstrated three 
discrete peaks of (200), (210), and (211) reflections at $2 \theta<5^{\circ}$ implying the presence of mesoporosity in both the supports maintained even after the immobilization of the Ru NPs. However, a decreasing trend in the intensity of the most distinctive peak with the increasing Ru loading was observed in the XRD patterns of both $\mathrm{Ru}(\mathrm{x}) @ S 1 \mathrm{~B}-\mathrm{C} 0$ and $\mathrm{Ru}(\mathrm{x}) @ S 1 \mathrm{~B}-\mathrm{C} 10$, which hinted at the distortion of the mesoporous structure of the supports to some extent. The deterioration of the mesoporosity could be credited to the refilling of the mesopores by the Ru NPs. The electronic density difference between the walls and the pores reduced gradually with the rise in the Ru NPs' loading and as a result, a decrease in the intensity of the diffraction peak was observed. The peaks slightly shifted to higher $2 \theta$ values after incorporation of the Ru NPs, which implied insufficient occupation of the mesopores by Ru NPs.
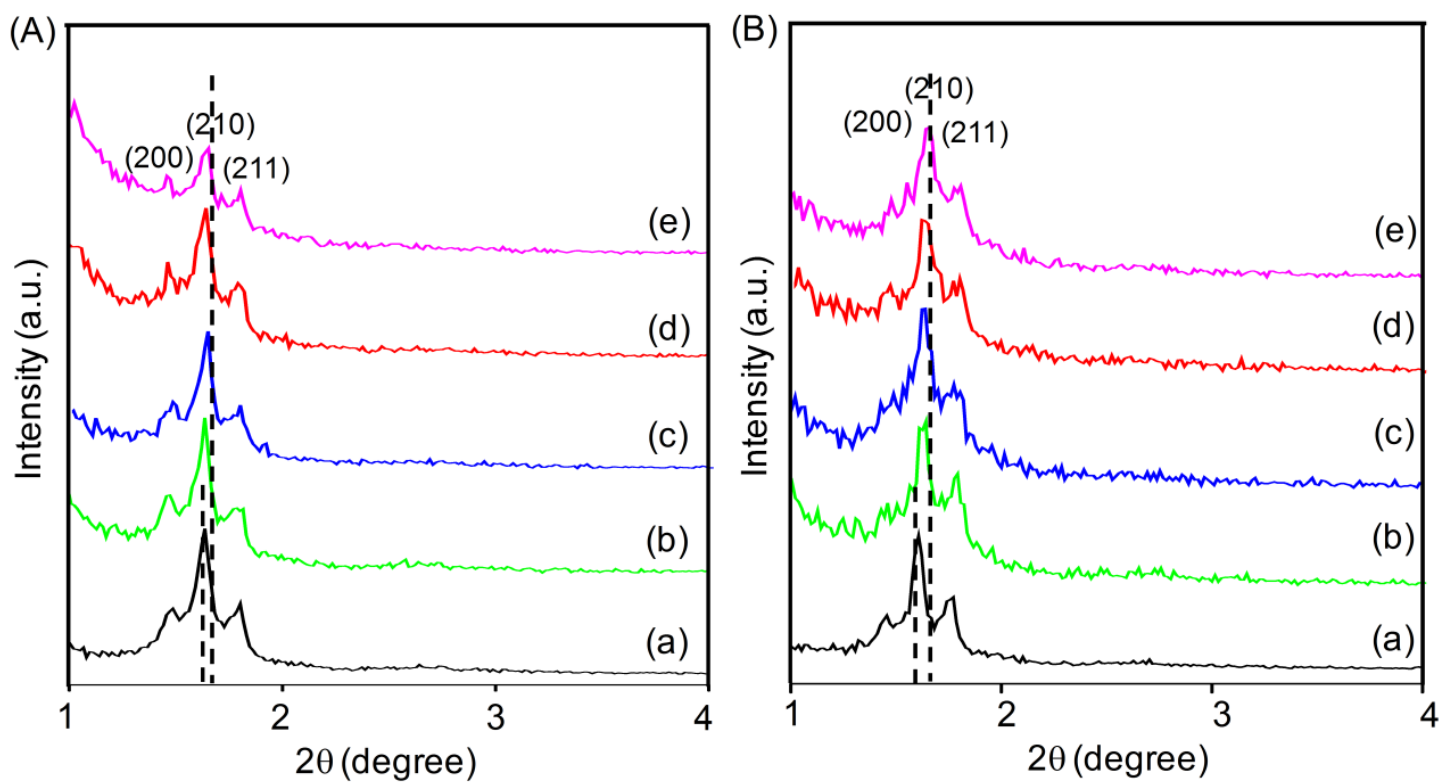

Figure 4. Small angle XRD (SXRD) patterns of $(A) R u(x) @ S 1 B-C 0$ and $(B) R u(x) @ S 1 B-C 10$, where $x=$ (a) 0 , (b) 0.5, (c) 1.0, (d) 2.0, and (e) $5.0 \mathrm{wt} \%$.

The incorporation of the Ru NPs within the mesopores was also realized from the decrease in surface areas and pore volumes of $\mathrm{Ru}(\mathrm{x}) @ \mathrm{~S} 1 \mathrm{~B}-\mathrm{C} 0$ and $\mathrm{Ru}(\mathrm{x}) @ S 1 \mathrm{~B}-\mathrm{C} 10$ in comparison to S1B-C0 and S1B-C10, respectively, determined from the $\mathrm{N}_{2}$ adsorption-desorption isotherms presented in Figure 5. Although both S1B-C0 and S1B-C10 exhibited type IV isotherms with two adsorption steps, the shapes changed after incorporation of the Ru NPs, which was particularly visible in the $\mathrm{N}_{2}$ adsorption-desorption isotherms of $\mathrm{Ru}(\mathrm{x}) @ S 1 B-\mathrm{C} 10$. Both pore volume and surface area of the supports decreased after incorporation of the Ru NPs, which suggested the effective immobilization of the NPs within the support. A significant drop in the pore volume of S1B-C10 compared to $\mathrm{Ru}(0.5) @ S 1 B-C 10$ was observed, which pointed out the filling of the mesopores in S1B-C10 by the Ru NPs. Homogenously distributed -COOH organic functional groups exist within the mesopores in S1B-C10, which served as the active sites for the growth of the Ru NPs via the electrostatic attraction between the $-\mathrm{COO}^{-}$and the Ru cations. The blocking of the mesopores by the Ru NPs reduced the support's pore volume. The surface area and pore volume were also reduced as the amount of Ru precursors increased, as shown in Table 1, that could be assigned to the formation of larger sized NPs. As the concentration of the metal precursor was increased, the reduction phenomenon took place at a faster rate, and ultimately could form Ru NPs of larger size. The filling of the mesopores by the large sized Ru NPs finally affected the surface areas and the pore volumes. The increase in the particle size with the increase in Ru precursor concentration could also be evidenced from the high resolution transmission electron microscopy HRTEM images of $\mathrm{Ru}(\mathrm{x}) @ \mathrm{~S} 1 \mathrm{~B}-\mathrm{C} 0$ and $\mathrm{Ru}(\mathrm{x}) @ \mathrm{~S} 1 \mathrm{~B}-\mathrm{C} 10$ presented in Figure 6. The average size of Ru NPs embedded in S1B-C0 increased from 2.8 to $4.6 \mathrm{~nm}$ when the 
amount of the Ru precursor was increased from 0.5 to $2.0 \mathrm{wt} \%$, as shown in Figure S2A. On the other hand, the particle size of Ru NPs embedded in S1B-C10 increased from 2.0 to $3.2 \mathrm{~nm}$ for the similar range of Ru precursor, as shown in Figure S2B. The particle size distribution histogram shown in the insets of Figure $6 \mathrm{~A}-\mathrm{c}, \mathrm{B}-\mathrm{c}$, indicated that the size of the Ru NPs affected by the presence of $-\mathrm{COOH}$ groups within the support.

Table 1. Textural properties of Ru(x)@S1B-C0 and Ru(x)@S1B-C10, where $\mathrm{x}=0.5,1.0,2.0$, and 5.0, and metal loadings determined by inductively coupled plasma optical emission spectrometer (ICP-OES).

\begin{tabular}{|c|c|c|c|c|}
\hline Sample & $\begin{array}{l}\text { Surface Area } \\
\qquad\left(\mathrm{m}^{2} \mathrm{~g}^{-1}\right)\end{array}$ & $\begin{array}{l}\text { Pore Volume } \\
\qquad\left(\mathrm{cm}^{3} \mathrm{~g}^{-1}\right)\end{array}$ & $\begin{array}{l}\text { Pore Size } \\
\quad(\mathrm{nm})\end{array}$ & $\begin{array}{l}\text { Ru Loading } \\
\text { (wt } \%)\end{array}$ \\
\hline S1B-C0 & 834 & 1.23 & 3.2 & - \\
\hline Ru(0.5)@S1B-C0 & 775 & 1.03 & 3.0 & 0.223 \\
\hline Ru(1)@S1B-C0 & 698 & 1.03 & 3.0 & 0.779 \\
\hline Ru(2)@S1B-C0 & 664 & 0.96 & 3.0 & 1.020 \\
\hline $\mathrm{Ru}(5) @ \mathrm{~S} 1 \mathrm{~B}-\mathrm{C} 0$ & 602 & 0.94 & 3.0 & 2.760 \\
\hline S1B-C10 & 850 & 1.84 & 3.0 & - \\
\hline $\mathrm{Ru}(0.5) @ S 1 B-C 10$ & 808 & 0.72 & 3.0 & 0.224 \\
\hline Ru(1)@S1B-C10 & 792 & 0.71 & 3.0 & 0.639 \\
\hline Ru(2)@S1B-C10 & 658 & 0.53 & 3.0 & 1.190 \\
\hline Ru(5)@S1B-C10 & 624 & 0.48 & 3.0 & 2.880 \\
\hline
\end{tabular}
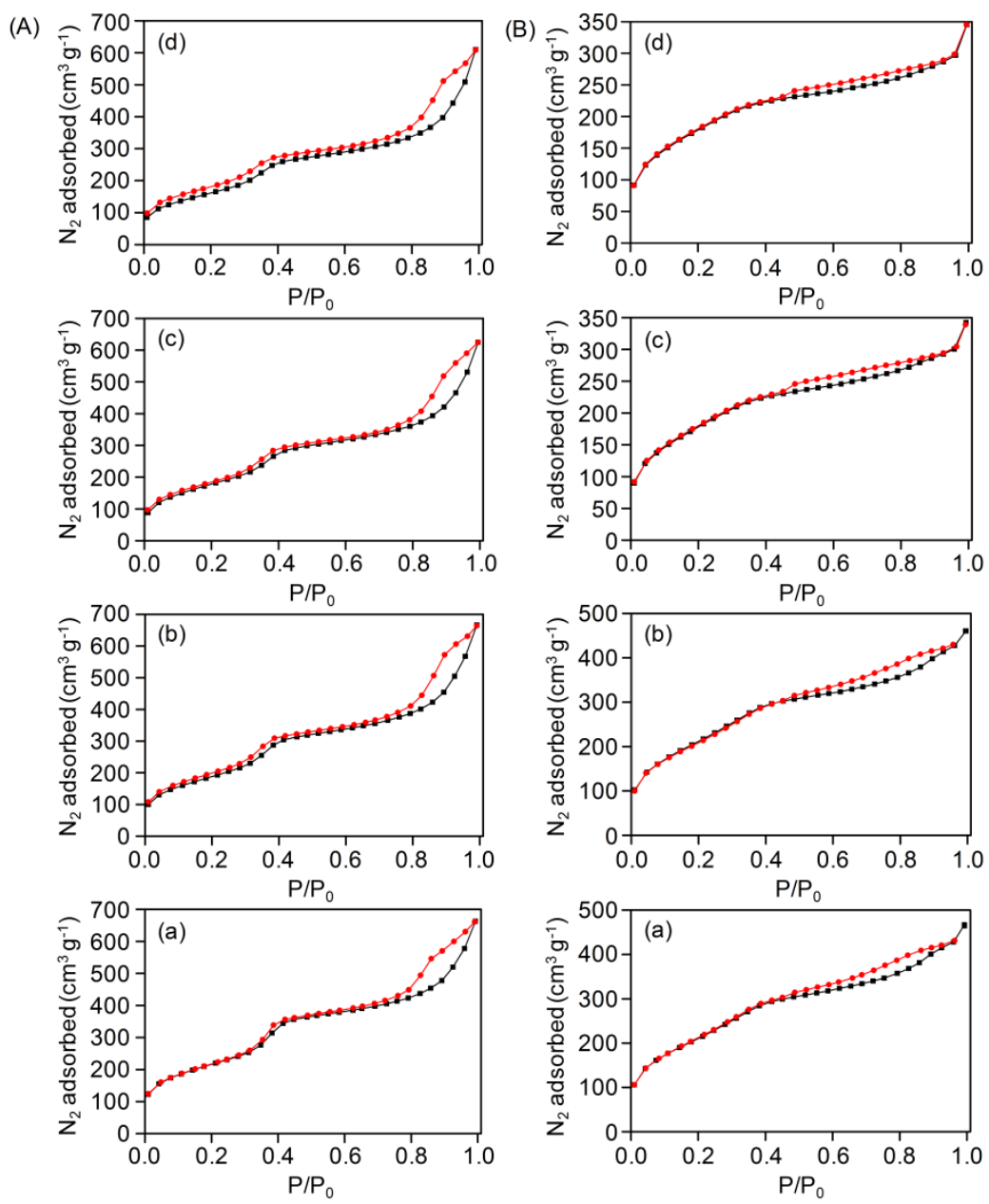

Figure 5. $\mathrm{N}_{2}$ sorption isotherms of $(A) \mathrm{Ru}(\mathrm{x}) @ S 1 B-C 0$ and $(\mathbf{B}) \mathrm{Ru}(\mathrm{x}) @ S 1 B-C 10$, where $\mathrm{x}=(\mathbf{a})$ 0.5, (b) 1.0, (c) 2.0, and (d) 5.0. 
(A)
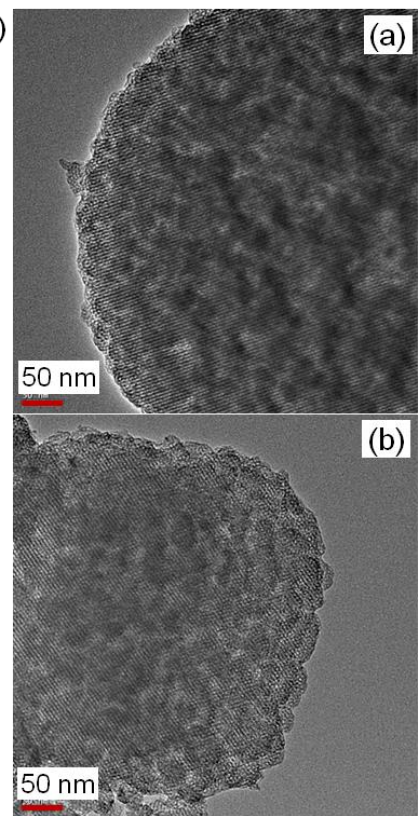

(c)

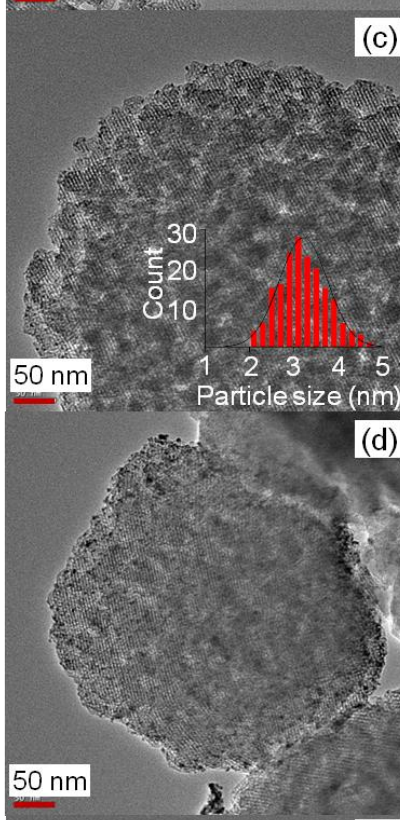

(e)

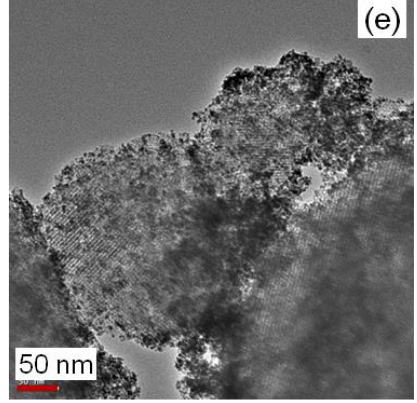

(B)

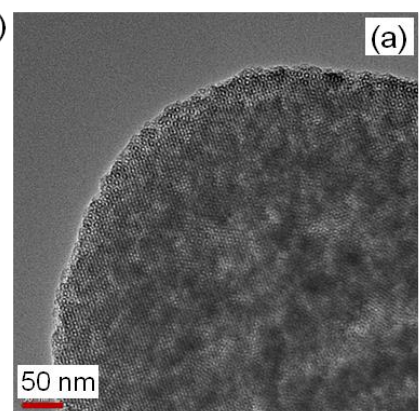

(b)

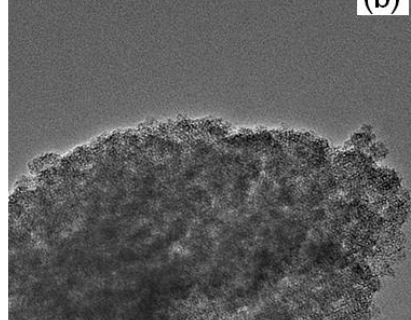

\section{$50 \mathrm{~nm}$}

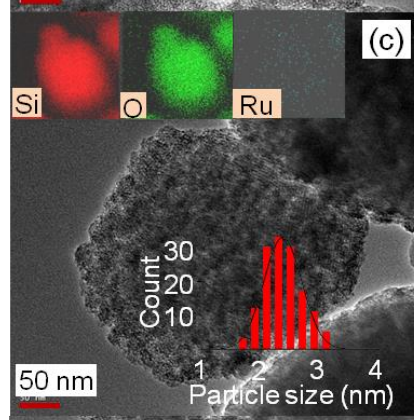

(d)
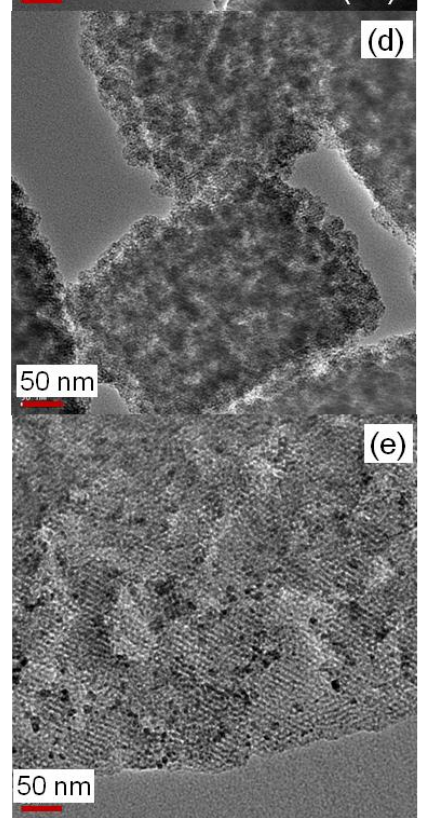

Figure 6. High resolution transmission electron microscopy HRTEM images of $(A) R u(x) @ S 1 B-C 0$ and (B) $\mathrm{Ru}(\mathrm{x}) @ S 1 B-C 10$, where $\mathrm{x}=$ (a) 0 (i.e., only support), (b) 0.5, (c) 1.0, (d) 2.0, and (e) $5.0 \mathrm{wt} \%$ of $\mathrm{Ru}$. The insets of $\mathbf{A}(\mathbf{c})$ and $\mathbf{B}(\mathbf{c})$ represent Ru particle size distribution within the support. Elemental mapping of Si, O, and Ru in Ru(1)@S1B-C10 is also presented. 
The average size of the Ru NPs was $2.4 \mathrm{~nm}$ when using S1B-C10 as the support (i.e., Ru(1)@S1B-C10), which was smaller than the Ru NPs' size ( 3.2 nm) when using S1B-C0 as the support (i.e., $\mathrm{Ru}(1) @ S 1 B-C 0$ ) for the same concentration of Ru precursor $(1 \mathrm{wt} \%)$. It was also observed that the Ru NPs were homogenously dispersed within the support. In order to visually determine the distribution of $\mathrm{Ru}$ within the support S1B-C10, the elemental mapping of $\mathrm{Ru}(1) @ S 1 B-C 10$ from scanning transmission electron microscopy STEM was performed. The mapping of $\mathrm{Si}, \mathrm{O}$, and $\mathrm{Ru}$ elements revealed that $\mathrm{Ru}$ NPs were distributed homogeneously within the support, as observed from the inset of Figure 6B-c. The co-existence of the - $\mathrm{COOH}$ organic groups, along with $-\mathrm{SiO}^{-}$in $\mathrm{S1B}-\mathrm{C} 10$, might induce electrostatic interactions with the highly positive $\mathrm{Ru}^{3+}$, which not only governed the effective adsorption of $\mathrm{Ru}^{3+}$, but also controlled the growth of Ru NPs during the chemical reduction process. On the other hand, the silanol groups on the mesopore surface of S1B-C0 might have a poor ability to bind $\mathrm{Ru}^{3+}$ species, and consequently Ru NPs with a large size were formed. Based on these results, it could be deduced that the -COOH groups in S1B-C10 not only controlled the Ru NPs' size, but also their distribution in the support. The wide angle XRD patterns presented in Figure S3 showed that no significant diffraction peak attributable to Ru NPs can be observed for Ru loadings of $0.5,1.0$, and $2.0 \mathrm{wt} \%$, indicating that either the Ru NPs were well dispersed within the supports or the metal loadings were too low to be detected by XRD. The - $\mathrm{COOH}$ and $-\mathrm{SiOH}$ groups in S1B-C10 might have enough capacity to absorb Ru species and retain the high dispersion. However, a weak diffraction peak at $2 \theta=43^{\circ}$ corresponding to the $\mathrm{Ru}(002)$ peak was observed at high Ru loading of $5 \mathrm{wt} \%$ in both the supports [46].

The oxidation states of the Ru NPs immobilized in S1B-C0 and S1B-C10 were further analyzed using the XPS technique. In the XPS survey scans of the surface of Ru(1)@S1B-C0 and Ru(1)@S1B-C10, as shown in Figure $\mathrm{S} 4$, the peaks corresponding to $\mathrm{C}, \mathrm{Ru}, \mathrm{Si}$, and $\mathrm{O}$ elements were detected. However, the overlapping of the $\mathrm{Ru} 3 \mathrm{~d}$ and $\mathrm{C} 1$ s peaks around $285 \mathrm{eV}$ made it difficult to confirm the presence of Ru. Therefore, XPS spectra of both Ru(x)@ S1B-C0 and Ru(x)@ S1B-C10 were acquired in the Ru $3 p$ region. The high resolution Ru 3p XPS spectra of Ru(x)@S1B-C0 and Ru(x)@S1B-C10 presented in Figure 7 showed two peaks at 462.9 and $485.3 \mathrm{eV}$, that could be endorsed to the Ru $3 \mathrm{p}_{3 / 2}$ and $\mathrm{Ru}$ $3 \mathrm{p}_{1 / 2}$ of metallic $\mathrm{Ru}(0)$ species [47]. The peaks around binding energies of 465.8 and $488.3 \mathrm{eV}$ were ascribed to the $\mathrm{Ru}(\mathrm{IV})$ state such as $\mathrm{RuO}_{2}$. It was observed that with the increase in the $\mathrm{Ru}$ loadings in the samples, the peak intensity also increased.

The catalytic activities of the prepared Ru-based catalysts were probed from $\mathrm{H}_{2}$ generation due to $\mathrm{AB}$ hydrolysis at room temperature. The supports $\mathrm{S} 1 \mathrm{~B}-\mathrm{C} 0$ and $\mathrm{S} 1 \mathrm{~B}-\mathrm{C} 10$ showed no $\mathrm{H}_{2}$ generation during hydrolysis, which implied that only Ru NPs were acting as the active catalysts for this reaction. The catalytic activities of $\mathrm{Ru}(\mathrm{x}) @ \mathrm{~S} 1 \mathrm{~B}-\mathrm{C} 0$ and $\mathrm{Ru}(\mathrm{x}) @ S 1 \mathrm{~B}-\mathrm{C} 10$ with varied $\mathrm{Ru}$ loadings within the range of 0.5 to $5 \mathrm{wt} \%$ were tested, and $\mathrm{H}_{2}$ generation versus time during the $\mathrm{AB}$ hydrolysis at $25^{\circ} \mathrm{C}$ plots are shown in Figure 8A,B. A stoichiometric amount of $\mathrm{H}_{2}(40 \mathrm{~mL})$ was generated in the presence of both the catalysts Ru(x)@S1B-C0 and Ru(x)@S1B-C10, where x stands for the Ru loadings of $0.5,1,2$, and $5 \mathrm{wt} \%$, respectively. The linear increase in the volume of the produced $\mathrm{H}_{2}$ with reaction time in the initial period for both the Ru-based catalysts suggested a zero-order reaction, which suggested that the external diffusion of the reactant had not limited the reaction. Taking into account the Ru active sites, the turnover frequencies (TOFs) of the catalysts were estimated by employing following equation:

$$
T O F=\frac{V_{\mathrm{H}_{2}}}{22.4 V_{s} C_{\mathrm{Ru}} t}
$$

where $\mathrm{V}_{\mathrm{H}_{2}}$ is the volume of $\mathrm{H}_{2}$ generation, $\mathrm{V}_{\mathrm{s}}$ is the volume of the solution, $\mathrm{t}$ is the time required for reaction completion, and $\mathrm{C}_{\mathrm{Ru}}$ is the Ru precursor concentration. The Ru loading of $1 \mathrm{wt} \%$ within both the supports S1B-C0 and S1B-C10 showed higher catalytic activities compared to other Ru loadings. However, $\mathrm{Ru}(1) @ S 1 B-C 10$ could generate $\mathrm{H}_{2}$ much faster than $\mathrm{Ru}(1) @ S 1 B-\mathrm{C} 0$, as can be seen from Figure $8 \mathrm{C}$. Obviously, $\mathrm{Ru}(1) @ S 1 \mathrm{~B}-\mathrm{C} 10$ exhibited the highest catalytic activity with a TOF value as high as $202 \mathrm{~mol} \mathrm{H}_{2} \mathrm{~mol}_{\mathrm{Ru}} \mathrm{min}^{-1}$ amongst all the catalysts. During the AB hydrolysis, the activation process is generally started on the catalyst surface by the development of active complex compounds $[11,48]$. 
The catalyst activity highly depends on its attraction towards the reaction intermediates. The $\mathrm{H}_{2} \mathrm{O}$ molecules attack the activated reaction intermediates and produce $\mathrm{BH}_{3}$ as the byproduct, which in turn generates $\mathrm{H}_{2}$ and boric acid upon hydrolysis. The higher catalytic activity of Ru(1)@S1B-C10 could be assigned to the nanosize dimension of the Ru particles and its homogenous dispersal inside the support. The smaller Ru NPs' size provided enormous active sites for the occurrence of the catalytic reaction. Because of the support's cubic mesoporous texture, the reactant molecules could quickly interact with the active sites of the Ru NPs and the product molecules could also come out easily through these pores. Thus, active sites' intrinsic activity and the pore confinement from the support might help to activate the reactants and promote the reaction. Although the size of Ru NPs in $\mathrm{Ru}(0.5) @ S 1 B-C 0$ was comparable to those in $\mathrm{Ru}(1) @ S 1 B-C 10$, the metal loading was much lower, resulting in its inferior catalytic activity. However, the obtained TOF value was comparable to those of other Ru-based catalysts on silica supports. The TOF values of some Ru-based catalysts on different supports reported in the literature for the hydrolysis of $\mathrm{AB}$ are given in Table 2 . The catalytic activity of $\mathrm{Ru}(1) @ S 1 B-C 10$ was similar to that of $\mathrm{Ru} @ S \mathrm{~S}_{2}$ core shell nanospheres where ultrafine $\mathrm{Ru}$ of size around $2 \mathrm{~nm}$ were embedded in a silica nanosphere of size around $25 \mathrm{~nm}$ [49]. Ru@SBA-15 showed higher catalytic activity than Ru(1)@S1B-C10, which could be attributed to the higher Ru loading in SBA-15 and the larger pore size of SBA-15 as compared to SBA-1 [50]. Although three dimensional pore arrangements in SBA-1 are more resistant to pore blocking and allow easier diffusion of the reactants inside the porous channel, the larger mesopores of the catalyst Ru@SBA-15 facilitate the transport of the reactants into the SBA-15 channels. As seen in Table 2, Ru(1)@S1B-C10 exhibited higher TOF values for $\mathrm{H}_{2}$ generation from the $\mathrm{AB}$ hydrolysis than other Ru-based catalysts, such as $\mathrm{Ru} / \mathrm{NC}-\mathrm{Fe}, \mathrm{Ru} 0 / \mathrm{ZrO} \mathrm{O}_{2}, \mathrm{Ru}(0) / \mathrm{SiO}_{2}-\mathrm{Fe}_{2} \mathrm{O}_{3}$, and $\mathrm{Ru} / \gamma-\mathrm{Al}_{2} \mathrm{O}_{3}$ [51-54]. The mesoporous channels in the catalyst acted as the transference paths for reactants and products during the catalysis. The activities of the metal NPs confined in mesoporous supports also depend on the unique textural properties of the support, chemical nature of the surface, and interactions among the metal NPs and the oxides. The higher catalytic activity of the catalyst Ru/HPCM (hierarchically porous carbon material) was attributed to the ultrafine Ru NPs, high porosity, and abundant nitrogen and oxygen-rich groups in the hierarchically porous carbon material (HPCM) support that facilitated the stabilization of Ru NPs and prohibited them from aggregation [28]. Being the most active amongst all the catalysts investigated here, $\mathrm{Ru}(1) @ S 1 \mathrm{~B}-\mathrm{C} 10$ was selected to analyze the effect of reaction temperature on the performance of the catalyst. The same catalyst was also used to evaluate the reusability.

The activation energy $\left(E_{a}\right)$ of the catalyst $\mathrm{Ru}(1) @ S 1 B-C 10$ was calculated by increasing the reaction temperature from 30 to $55^{\circ} \mathrm{C}$. As depicted in Figure 8D, the rate of $\mathrm{H}_{2}$ generation increased with the elevation of the temperature reaction. The values of rate constants $k$ at different temperatures were calculated from the slope of the linear portion of each plot. $E_{a}$ was evaluated to be nearly $24.13 \mathrm{~kJ} \mathrm{~mol}^{-1}$ from the Arrhenius plot of $\ln (\mathrm{k})$ versus $1 / \mathrm{T}$, as shown in the inset of Figure $8 \mathrm{D}$, employing the following equation:

$$
\ln \mathrm{k}=-\frac{\mathrm{E}_{\mathrm{a}}}{\mathrm{RT}}+\ln \mathrm{A}
$$

where $\mathrm{R}$ is the ideal gas constant, $\mathrm{A}$ is the pre-exponential factor, and $\mathrm{T}$ is the reaction temperature in Kelvin. The estimated $E_{a}$ value was lower than most of the reported values for the same reaction by using different catalysts, as shown in Table 2, which implied that the Ru(1)@S1B-C10 catalyst is a very promising candidate for the hydrolysis of $\mathrm{AB}$. 

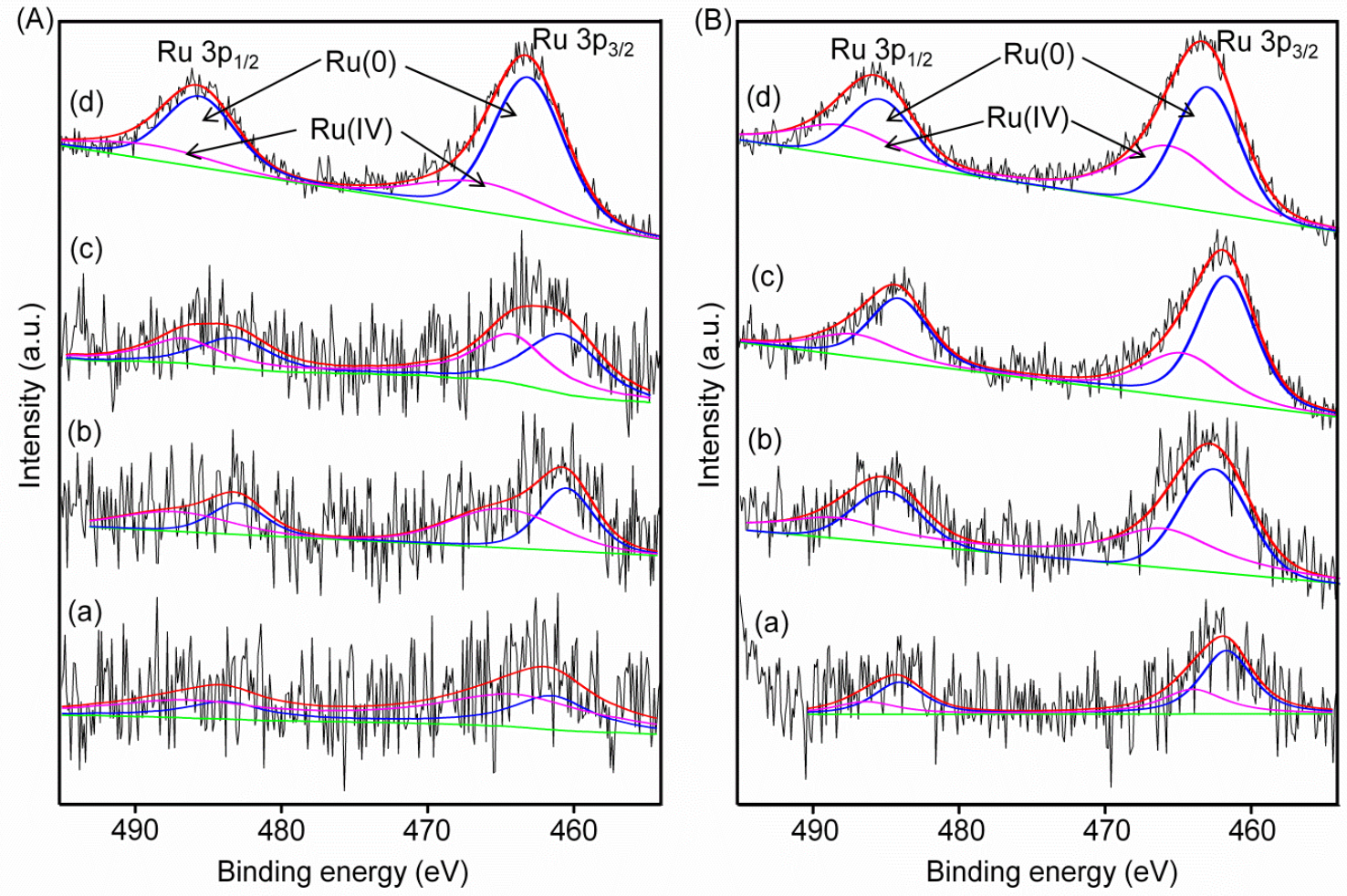

Figure 7. XPS spectra of Ru 3p peaks of the (A) Ru(x)@S1B-C0 and (B) Ru(x)@S1B-C10, where $x$ represents (a) 0.5, (b) 1.0, (c) 2.0, and (d) $5.0 \mathrm{wt} \%$ Ru loading.
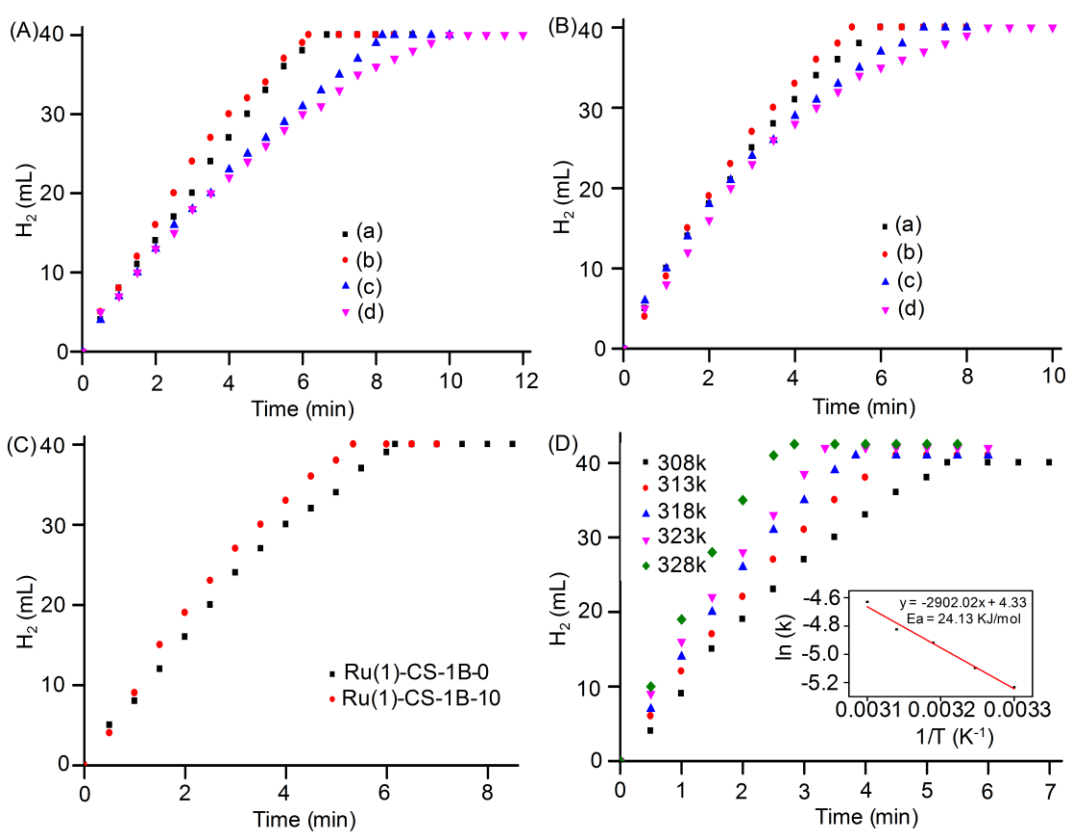

Figure 8. $\mathrm{H}_{2}$ generation from ammonia borane $(\mathrm{AB})$ aqueous solution catalyzed by $(\mathrm{A}) \mathrm{Ru}(\mathrm{x}) @ \mathrm{~S} 1 \mathrm{~B}-\mathrm{C} 0$ and (B) Ru(x)@S1B-C10, (C) Ru(1)@S1B-C0 and Ru(1)@S1B-C0, and (D) Ru(1)@S1B-C10 at different reaction temperatures. Arrhenius plots of $\ln (\mathrm{k})$ versus $1 / \mathrm{T}$ is shown in the inset of $(\mathrm{D})$. 
Table 2. Catalytic activity of various Ru-based catalysts for $\mathrm{H}_{2}$ generation from aqueous $A B$.

\begin{tabular}{|c|c|c|c|}
\hline Catalysts & $\begin{array}{c}\text { TOF } \\
\left(\mathrm{mol} \mathrm{H}_{2} \mathrm{~min}^{-1} \operatorname{mol}_{\mathrm{Ru}}{ }^{-1}\right)\end{array}$ & $\begin{array}{c}\mathrm{E}_{\mathrm{a}} \\
\left(\mathrm{kJ} \mathrm{\textrm {mol } ^ { - 1 }}\right)\end{array}$ & Ref. \\
\hline $\mathrm{Ru}(1) @ S 1 B-C 10$ & 202.4 & 24.13 & This work \\
\hline Ru(1)@S1B-C0 & 175.0 & 30.06 & This work \\
\hline $\mathrm{Ru} / \mathrm{HPCM}$ & 440 & 43.0 & [28] \\
\hline $\mathrm{Ru} @ \mathrm{SiO}_{2}$ & 200 & 38.2 & [49] \\
\hline Ru@SBA-15 & 316 & 34.8 & [50] \\
\hline $\mathrm{Ru} / \mathrm{NC}-\mathrm{Fe}$ & 102.9 & 47.42 & [51] \\
\hline $\mathrm{Ru}^{0} / \mathrm{ZrO}_{2}$ & 173 & 58 & [52] \\
\hline $\mathrm{Ru}(0) / \mathrm{SiO}_{2}-\mathrm{Fe}_{2} \mathrm{O}_{3}$ & 127 & 54 & [53] \\
\hline 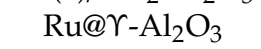 & 77 & 23 & [54] \\
\hline
\end{tabular}

The reusability of $\mathrm{Ru}(1) @ S 1 B-\mathrm{C} 10$ for $\mathrm{H}_{2}$ from $\mathrm{AB}$ hydrolysis was also explored. The plot of mol $\mathrm{H}_{2} / \mathrm{mol} \mathrm{AB}$ versus time for $\mathrm{Ru}(1) @ S 1 B-C 10$ catalyzed $\mathrm{AB}$ hydrolysis from the first to fifth cycle at $25^{\circ} \mathrm{C}$ is shown in Figure 9A. It was observed that the total conversion of $\mathrm{AB}$ could be accomplished with generation of three equivalents of $\mathrm{H}_{2}$ per mole of $\mathrm{AB}$ in each run. However, the reaction rates decreased with the increasing number of recycling. To explore the deterioration of the activity, the amount of $\mathrm{Ru}$ in the catalyst $\mathrm{Ru}(1) @ S 1 B-C 10$ after being used for five cycles was detected by ICP. The amount of $\mathrm{Ru}$ in $\mathrm{Ru}(1) @ S 1 \mathrm{~B}-\mathrm{C} 10$ after being used for five cycles was $0.423 \mathrm{wt} \%$ compared to that of $0.639 \mathrm{wt} \%$ in the fresh sample. Therefore, it was speculated that some Ru NPs were leached out during the separation after completion of each cycle and, as a result, catalytic activity decreased. Due to the use of catalysts for several cycles, metaborate ions could have adsorbed on its surface, which restricted the accession of the reactants to the Ru NP active sites that might be another possibility for the lower catalytic performance.

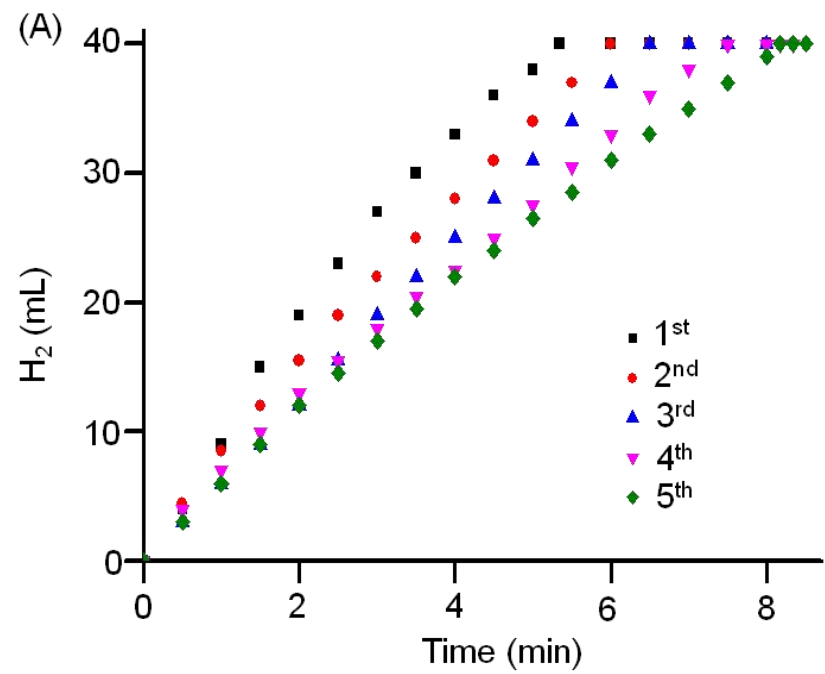

(B)

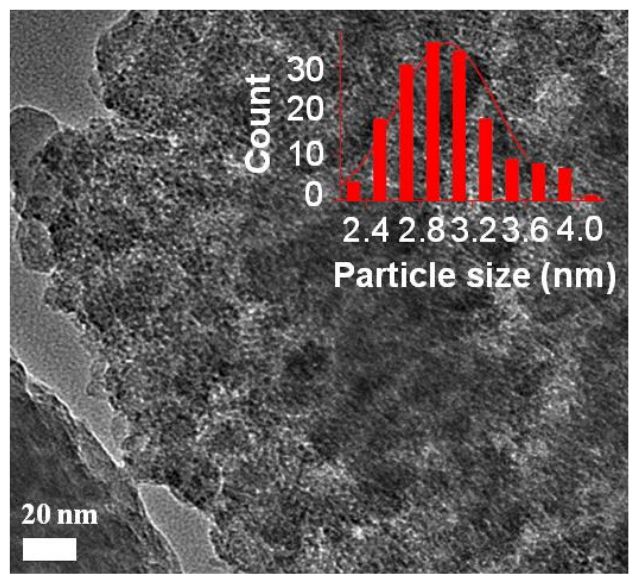

Figure 9. (A) $\mathrm{H}_{2}$ generation from $\mathrm{AB}$ by $\mathrm{Ru}(1) @ S 1 B-C 10$ catalyst from 1 st to 5 th cycle at $25^{\circ} \mathrm{C}$; (B) TEM image of the five-times recycled $\mathrm{Ru}(1) @ S 1 \mathrm{~B}-\mathrm{C} 10$. The inset picture shows the particle size distribution after being reused five times.

The recycled catalysts were further characterized by XRD and TEM analysis. As shown in Figure S5, the wide angle XRD pattern of the recycled Ru(1)@S1B-C10 catalyst was comparable to the fresh catalyst, which implied that there was no significant change in the microstructural property after being used for several cycles. The TEM image of the reused catalyst given in Figure 9B pointed out that the morphology of Ru NPs within the support S1B-C10 remained unaltered, but the size of the Ru NPs increased marginally to $3.1 \mathrm{~nm}$, as shown in the inset of Figure 9B. 


\section{Materials and Methods}

\subsection{Materials}

Sigma-Aldrich (Steinheim, Germany) provided TEOS, CPC, PAA (35\% in solution), and $\mathrm{RuCl}_{3} \cdot \mathrm{nH}_{2} \mathrm{O}$. CES 25 wt \% was supplied by Gelest. All chemicals were commercially available and used without further purification.

\subsection{Synthesis of S1B-C0 and S1B-C10}

Pure SBA-1 (S1B-C0) and SBA-1 functionalized with -COOH (S1B-C10) were produced by adopting the already described synthesis procedures with minor alterations [55]. In a typical synthesis procedure, CPC $(0.54 \mathrm{~g})$ and PAA $(2.66 \mathrm{~g})$ were dispersed in deionized water $(25 \mathrm{~mL})$ and stirred at $25^{\circ} \mathrm{C}$ until a clear solution was obtained. $\mathrm{NH}_{4} \mathrm{OH}(3.0 \mathrm{~g})$ was then added quickly into the solution and stirred for an additional $20 \mathrm{~min}$. Afterwards, TEOS ( $2.08 \mathrm{~g}$ ) was mixed into the solution and blended for another $30 \mathrm{~min}$, transferred into an autoclave, and hydrothermally treated at $80^{\circ} \mathrm{C}$ for $48 \mathrm{~h}$. To prepare the -COOH functionalized S1B-C10, a solution mixture of TEOS (1.248 g) and CES (3.136 g) was made before hydrothermal treatment. As-synthesized materials were obtained after filter. The as-synthesized material $(0.6 \mathrm{~g})$ was mixed with $\mathrm{HNO}_{3}(10.0 \mathrm{~g})$ and tetrahydrofuran THF $(100 \mathrm{~mL})$ and heated at $60{ }^{\circ} \mathrm{C}$ for $3 \mathrm{~h}$ to remove the template. The process was repeated twice to obtain SBA- 1 and -COOH functionalized SBA-1. The number 10 in S1B-C10 represents the loading level of -COOH functional groups, which can be determined by ${ }^{29} \mathrm{Si}$ solid state NMR spectroscopy.

\subsection{Synthesis of $R u(x) S 1 B-C 0$ and $R u(x) @ S 1 B-C 10$}

A double chemical reduction approach was used to prepare S1B-C0 and S1B-C10 supported Ru NPs. $\mathrm{NH}_{3} \mathrm{BH}_{3}$ and $\mathrm{NaBH}_{4}$ were used as the reducing agents during the synthesis. In the typical synthesis process, the support $\left(0.1 \mathrm{~g}\right.$, S1B-C0/S1B-C10) was first dispersed in $\mathrm{RuCl}_{3} \cdot \mathrm{nH}_{2} \mathrm{O}(0.001 \mathrm{M})$ and mixed for $24 \mathrm{~h}$ and then kept in an ultrasonicator for $1 \mathrm{~h}$. Reducing agents $\mathrm{NaBH}_{4}$ and $\mathrm{NH}_{3} \mathrm{BH}_{3}$ were mixed in distilled water initially and then added to the Ru precursor solution drop by drop and stirred intensely till the bubbles vanished. The solid samples were obtained by centrifugation, followed by washing with distilled water and drying. The concentration of the Ru precursor solution was varied in order to prepare the samples with different $\mathrm{Ru}$ loadings. The molar ratio of the various components was set as $1 \mathrm{RuCl}_{3} \cdot \mathrm{nH}_{2} \mathrm{O}: 54 \mathrm{NH}_{3} \mathrm{BH}_{3}: 8.8 \mathrm{NaBH}_{4}: 18600 \mathrm{H}_{2} \mathrm{O}$. The prepared materials were named as $\mathrm{Ru}(\mathrm{x}) @ S 1 \mathrm{~B}-\mathrm{C} 0$ and $\mathrm{Ru}(\mathrm{x}) @ \mathrm{~S} 1 \mathrm{~B}-\mathrm{C} 10$, where $\mathrm{x}$ represented the $\mathrm{Ru}$ loading (wt \%) in the reaction mixture.

\subsection{Characterization Methods}

The crystallinity and the structural orders of the prepared Ru(x)@S1B-C0 and Ru(x)@S1B-C10 were analyzed using an X-ray diffractometer (Lab-x XRD-6000 SHIMADZU) and a Wiggler-A beam line $(\lambda=0.133367 \mathrm{~nm})$ in National Synchrotron Radiation Research Center, Taiwan, respectively. The textural properties of S1B-C0, S1B-C10, Ru(x)@S1B-C0, and Ru(x)@S1B-C10 were explored from the $\mathrm{N}_{2}$ adsorption-desorption isotherms with an Autosorb iQ2 at $77 \mathrm{~K}$. The Barrett-Joyner-Halenda $(\mathrm{BJH})$ method was employed to estimate the pore size and pore volume. Ru NP size distributions and structural orders were obtained using TEM (JEOL JEM2100). A JASCO FTIR-4100 was used to corroborate the existence of -COOH groups in S1B-C10. Then, ${ }^{29} \mathrm{Si}$ MAS (magic angle spinning) and ${ }^{13} \mathrm{C} C P M A S$ (cross polarization magic angle spinning) NMR spectra were acquired by a Varian Infinityplus-500 NMR spectrometer. The chemical state of Ru NPs was characterized by XPS analysis using a Thermo VG Scientific Sigma Probe spectrometer. Zetasizer Nano-ZS90 (Malvern) was used to assess the zeta potential. The actual Ru amounts in Ru(x)@S1B-C0 and Ru(x)@S1B-C10 were estimated using a Jarrell-Ash, ICAP 9000, an inductively coupled plasma optical emission spectrometer (ICP-OES). 


\subsection{Hydrolysis of Ammonia Borane by Ru(x)@S1B-C0 and Ru(x)@S1B-C10}

The activity of the catalysts $\mathrm{Ru}(\mathrm{x}) @ \mathrm{~S} 1 \mathrm{~B}-\mathrm{C} 0$ and $\mathrm{Ru}(\mathrm{x}) @ \mathrm{~S} 1 \mathrm{~B}-\mathrm{C} 10$ for the hydrolysis of AB were evaluated from the $\mathrm{H}_{2}$ generation rate due to the hydrolysis of $\mathrm{AB}$ [56]. In the typical experimental procedure, catalyst and $\mathrm{NH}_{3} \mathrm{BH}_{3}$ (molar ratio $\sim 0.05$ ) were put into a round-bottom flask, thermostated at $30^{\circ} \mathrm{C}$, and followed by the addition of water $(5 \mathrm{~mL})$. A glass burette filled with water was connected to the reaction flask and the volume of $\mathrm{H}_{2}$ released was determined from the change of water level in the burette. The measurement carried out till the bubbles disappeared. The temperature of the reaction varied within the range 30 to $55^{\circ} \mathrm{C}$ to calculate the activation energy.

The reusability of the catalyst was accessed by repeating the $\mathrm{AB}$ hydrolysis experiments five times by the same catalyst, $\mathrm{Ru}(1) @ S 1 \mathrm{~B}-\mathrm{C} 10$. After completion of each cycle, the catalyst was extracted from the aqueous solution by centrifugation, washed with water, and dried for $24 \mathrm{~h}$.

\section{Conclusions}

Herein, we demonstrated a successful synthesis of Ru NPs inside the channels of SBA-1 using the double chemical reduction approach. Prior to encapsulation of the Ru NPs, the mesoporous silica support was functionalized with - $\mathrm{COOH}$ organic groups to study the effect of organic groups on the formation of Ru NPs. The characterization results of Ru(x)@S1B-C0 and Ru(x)@S1B-C10 showed that the $-\mathrm{COOH}$ organic functional groups distributed within the support play a prominent part in the dispersion and size of the formed Ru NPs. The strong electrostatic interactions between $\mathrm{Ru}^{3+}$ and $-\mathrm{COO}^{-}$at high $\mathrm{pHs}$ could efficiently confine the Ru NPs inside the mesopores and restrain the NPs from agglomeration. The prepared $\mathrm{Ru}(\mathrm{x}) @ \mathrm{~S} 1 \mathrm{~B}-\mathrm{C} 0$ and $\mathrm{Ru}(\mathrm{x}) @ \mathrm{~S} 1 \mathrm{~B}-\mathrm{C} 10$ catalysts exhibited improved catalytic activity towards the hydrolytic dehydrogenation of $\mathrm{AB}$ under ambient temperature. In particular, $\mathrm{Ru}(1) @ S 1 B-C 10$ exhibited excellent catalytic performance with a TOF value of $202 \mathrm{~mol} \mathrm{H}_{2} \mathrm{~mol}_{\mathrm{Ru}}$ $\mathrm{min}^{-1}$, due to the collective contribution from a small particle size and its homogenous dispersion, and exceptional porous structure of the support. The catalyst also revealed good reuse capacity as the cage-type mesopores of the support inhibited metal leaching, and thus the active sites of the catalysts remained intact.

Supplementary Materials: The following are available online at http://www.mdpi.com/2073-4344/10/3/267/s1, Figure S1: Zeta potentials of (a) S1B-C0 and (b) S1B-C10, Figure S2: High magnification HRTEM images of (A) $\mathrm{Ru}(\mathrm{x}) @ S 1 \mathrm{~B}-\mathrm{C} 0$ and $(\mathrm{B}) \mathrm{Ru}(\mathrm{x}) @ \mathrm{~S} 1 \mathrm{~B}-\mathrm{C} 10$, where $\mathrm{x}=(\mathrm{a}) 0.5$, (b) 1.0, and (c) $2.0 \mathrm{wt} \%$, Figure S3: Wide angle XRD patterns (A) $\mathrm{Ru}(\mathrm{x}) @ S 1 \mathrm{~B}-\mathrm{C} 0$ and $(\mathrm{B}) \mathrm{Ru}(\mathrm{x}) @ \mathrm{~S} 1 \mathrm{~B}-\mathrm{C} 10$, where $\mathrm{x}=$ (a) 0.5, (b) 1.0, (c) 2.0, and (d) $5.0 \mathrm{wt} \%$, Figure S4: XPS Survey spectra of (A) Ru(1)@S1B-C0, and (B) Ru(1)@S1B-C10, Figure S5: Wide angle XRD patterns of fresh and recycled $\mathrm{Ru}(1) @ \mathrm{~S} 1 \mathrm{~B}-\mathrm{C} 10$.

Author Contributions: Conceptualization (J.R.D., D.S., and H.-M.K.); Data curation (J.R.D. and K.-S.H.); Formal analysis (J.R.D., D.S., K.-S.H., and H.-M.K.); Funding acquisition (H.-M.K., Y.-C.Y., and C.-S.C.); Methodology (J.R.D. and K.-S.H.); Supervision (H.-M.K.); Writing-original draft (J.R.D. and D.S.); Writing-review \& editing (H.-M.K., Y.-C.Y., and C.-S.C.). All authors have read and agreed to the published version of the manuscript.

Funding: This work was financially supported by the Ministry of Science and Technology (MOST 108-2113-M-008-009, MOST 106-2113-M-182-002), Chang-Gung Memorial Hospital (CMRPD5J0011), National Taipei University of Technology.

Conflicts of Interest: The authors declare no conflict of interest.

\section{References}

1. Chen, P.; Xiong, Z.; Luo, J.; Lin, J.; Tan, K.L. Interaction of hydrogen with metal nitrides and imides. Nature 2002, 420, 302-304. [CrossRef]

2. Graetz, J. New approaches to hydrogen storage. Chem. Soc. Rev. 2009, 38, 73-82. [CrossRef]

3. Hamilton, C.W.; Baker, R.T.; Staubitz, A.; Manners, I. B-N compounds for chemical hydrogen storage. Chem. Soc. Rev. 2009, 38, 279-293. [CrossRef]

4. Orimo, S.; Nakamori, Y.; Eliseo, J.R.; Züttel, A.; Jensen, C.M. Complex hydrides for hydrogen storage. Chem. Rev. 2007, 107, 4111-4132. [CrossRef] 
5. Nunes, H.; Ferreira, M.; Rangel, C.; Pinto, A. Hydrogen generation and storage by aqueous sodium borohydride $\left(\mathrm{NaBH}_{4}\right)$ hydrolysis for small portable fuel cells $\left(\mathrm{H}_{2}-\mathrm{PEMFC}\right)$. Int. J. Hydrogen Energy 2016, 41, 15426-15432. [CrossRef]

6. Li, X.; Fan, G.; Zeng, C. Synthesis of ruthenium nanoparticles deposited on graphene-like transition metal carbide as an effective catalyst for the hydrolysis of sodium borohydride. Int. J. Hydrogen Energy 2014, 39, 14927-14934. [CrossRef]

7. Wu, Z.; Duan, Y.; Ge, S.; Yip, A.C.K.; Yang, F.; Li, Y.; Dou, T. Promoting hydrolysis of ammonia borane over multiwalled carbon nanotube-supported Ru catalysts via hydrogen spillover. Catal. Commun. 2017, 91, 10-15. [CrossRef]

8. Demirci, U.B. Ammonia borane, a material with exceptional properties for chemical hydrogen storage. Int. J. Hydrogen Energy 2017, 42, 9978-10013. [CrossRef]

9. Wu, D.; Wen, M.; Gu, C.; Wu, Q. 2D NiFe/CeO 2 basic-site-enhanced catalyst via in-situ topotactic reduction for selectively catalyzing the $\mathrm{H}_{2}$ generation from $\mathrm{N}_{2} \mathrm{H}_{4} \cdot \mathrm{H}_{2} \mathrm{O}$. ACS Appl. Mater. Interfaces 2017, 9, 16103-16108. [CrossRef]

10. Pan, Y.; Pan, C.L.; Zhang, Y.; Li, H.; Min, S.; Guo, X.; Zheng, B.; Chen, H.; Anders, A.; Lai, Z.; et al. Selective hydrogen generation from formic acid with well-defined complexes of ruthenium and phosphorus-nitrogen $\mathrm{PN}^{3}$-pincer ligand. Chem. Asian J. 2016, 11, 1357-1360. [CrossRef]

11. Lu, Z.-H.; Jiang, H.L.; Yadav, M.; Aranishi, K.; Xu, Q. Synergistic catalysis of Au-Co@SiO 2 nanospehere in hydrolytic dehydrogenation of ammonia borane for chemical hydrogen storage. J. Mater. Chem. 2012, 22, 5065-5071. [CrossRef]

12. Grochala, W.; Edwards, P.P. Thermal decomposition of the non-interstitial hydrides for the storage and production of hydrogen. Chem. Rev. 2004, 104, 1283-1316. [CrossRef]

13. Ramzan, M.; Silvearv, F.; Blomqvist, A.; Scheicher, R.H.; Lebegue, S.; Ahuja, R. Structural and energetic analysis of the hydrogen storage materials $\mathrm{LiNH}_{2} \mathrm{BH}_{3}$ and $\mathrm{NaNH}_{2} \mathrm{BH}_{3}$ from ab initio calculations. Phys. Rev. B 2009, 79, 132102. [CrossRef]

14. Rakap, M.; Özkar, S. Hydrogen generation from the hydrolysis of ammonia borane using intrazeolite cobalt $(0)$ nanoclusters catalyst. Int. J. Hydrogen Energy 2010, 35, 3341-3346. [CrossRef]

15. Jiang, H.L.; Xu, Q. Catalytic hydrolysis of ammonia borane for chemical hydrogen storage. Catal. Today 2011, 170, 56-63. [CrossRef]

16. Mohajeri, N.; Raissi, A.T.; Adebiyi, O. Hydrolytic cleavage of ammonia-borane complex for hydrogen production. J. Power Sources 2007, 167, 482-485. [CrossRef]

17. Ramachandran, P.V.; Gagare, P.D. Preparation of ammonia borane in high yield and purity, methanolysis, and regeneration. Inorg. Chem. 2007, 46, 7810-7817. [CrossRef]

18. Erdogan, H.; Metin, Ö.; Özkar, S. In situ-generated PVP-stabilized palladium (0) nanocluster catalyst in hydrogen generation from the methanolysis of ammonia-borane. Phys. Chem. Chem. Phys. 2009, 11, 10519-10525. [CrossRef]

19. Sun, D.H.; Mazumder, V.; Metin, Ö.; Sun, S.H. Methanolysis of ammonia borane by CoPd nanoparticles. ACS Catal. 2012, 2, 1290-1295. [CrossRef]

20. Li, Z.; Zhu, G.; Lu, G.; Qiu, S.; Yao, X. Ammonia borane confined by a metal-organic framework for chemical hydrogen storage: Enhancing kinetics and eliminating ammonia. J. Am. Chem. Soc. 2010, 132, 1490-1491. [CrossRef]

21. Moury, R.; Moussa, G.; Demirci, U.B.; Hannauer, J.; Bernard, S.; Petit, E.; van der Lee, A.; Miele, P. Hydrazine borane: Synthesis, characterization, and application prospects in chemical hydrogen storage. Phys. Chem. Chem. Phys. 2012, 14, 1768-1777. [CrossRef]

22. Marder, T.B. Will we soon be fueling our automobiles with ammonia-borane? Angew. Chem. Int. Ed. 2007, 46, 8116-8118. [CrossRef]

23. Zahmakiran, M.; Özkar, S. Transition metal nanoparticles in catalysis for the hydrogen generation from the hydrolysis of ammonia-borane. Top. Catal. 2013, 56, 1171-1183. [CrossRef]

24. Aijaz, A.; Karkamkar, A.; Choi, Y.J.; Tsumori, N.; Rönnebro, E.; Autrey, T.; Shioyama, H.; Xu, Q. Immobilizing highly catalytically active pt nanoparticles inside the pores of metal-organic framework: A double solvents approach. J. Am. Chem. Soc. 2012, 134, 13926-13929. [CrossRef]

25. Xi, P.; Chen, F.; Xie, G.; Ma, C.; Liu, H.; Shao, C.; Wang, J.; Xu, Z.; Xu, X.; Zhang, Z. Ultrathin S-doped MoSe 2 nanosheets for efficient hydrogen evolution. Nanoscale 2014, 4, 5597-5601. [CrossRef] 
26. Fuku, R.; Hayashi, K.; Takakura, S.; Kamegawa, T.; Mori, K.; Yamashita, H. The synthesis of size- and color-controlled silver nanoparticles by using microwave heating and their enhanced catalytic activity by localized surface plasmon resonance. Angew. Chem. Int. Ed. 2013, 52, 7446-7450. [CrossRef]

27. Fan, G.; Liu, Q.; Tang, D.; Li, X.; Bi, J.; Gao, D. Nanodiamond supported Ru nanoparticles as an effective catalyst for hydrogen evolution from hydrolysis of ammonia borane. Int. J. Hydrogen Energy 2016, 41, 1542-1549. [CrossRef]

28. Zhong, F.; Wang, Q.; Xu, C.; Yang, Y.; Wang, Y.; Zhang, Y.; Gao, D.; Jian, B.; Fan, G. Ultrafine and highly dispersed Ru nanoparticles supported on nitrogen-doped carbon nanosheets: Efficient catalysts for ammonia borane hydrolysis. Appl. Surf. Sci. 2018, 455, 326-332. [CrossRef]

29. Xu, C.; Ming, M.; Wang, Q.; Yang, C.; Fan, G.; Wang, Y.; Gao, D.; Bi, J.; Zhang, Y. Facile synthesis of effective $\mathrm{Ru}$ nanoparticles on carbon by adsorption-low temperature pyrolysis strategy for hydrogen evolution. J. Mater. Chem. A 2018, 6, 14380-14386. [CrossRef]

30. Yao, Q.L.; Lu, Z.H.; Huang, W.; Chen, X.; Zhu, J. High Pt-like activity of the Ni-Mo/graphene catalyst for hydrogen evolution from hydrolysis of ammonia borane. J. Mater. Chem. A 2016, 4, 8579-8583. [CrossRef]

31. Xu, D.Y.; Dai, P.; Liu, X.M.; Cao, C.Q.; Guo, Q.J. Carbon-supported cobalt catalyst for hydrogen generation from alkaline sodium borohydride solution. J. Power Sources 2008, 182, 616-620. [CrossRef]

32. Zou, X.X.; Huang, X.X.; Goswami, A.; Silva, R.; Sathe, B.R.; Mikmekova, E.; Asefa, T. Cobalt-embedded nitrogen-rich carbon nanotubes efficiently catalyze hydrogen evolution reaction at all pH values. Angew. Chem. Int. Ed. 2014, 53, 4372-4376. [CrossRef]

33. Yu, J.; Hsieh, C.-C.; Chen, P.-Y.; Weng, B.-J.; Chen-Yang, Y.W. Highly active and reusable silica-aerogel-supported platinum-cobalt bimetallic catalysts for the dehydrogenation of ammonia borane. RSC Adv. 2016, 6, 112109-112116. [CrossRef]

34. Luo, Y.C.; Liu, Y.S.; Huang, Y.; Liu, X.Y.; Mou, C.Y. Mesoporous silica supported cobalt catalysts for hydrogen generation in hydrolysis of ammonia borane. Int. J. Hydrogen Energy 2013, 37, 7280-7290. [CrossRef]

35. Arbiol, J.; Cabot, A.; Morante, J.R.; Chen, F.; Liu, M. Distributions of noble metal Pd and Pt in mesoporous silica. Appl. Phys. Lett. 2002, 81, 3449-3451. [CrossRef]

36. Yang, C.; Sheu, H.; Chao, K. Templated synthesis and structural study of densely packed metal nanostructures in MCM-41 and MCM-48. Adv. Funct. Mater. 2002, 12, 143-148. [CrossRef]

37. Li, X.; Liu, X.; Yang, Y.; Zhao, J.; Li, C.; Yang, Q. Entrapment of metal nanoparticles within nanocages of mesoporous silicas aided by co-surfactants. J. Mater. Chem. 2012, 22, 21045-21050. [CrossRef]

38. Zhao, Y.X.; Zhang, Y.H.; Chen, J.; Li, J.L.; Liew, K.; Nordin, M.R.B. SBA-16-Supported Cobalt catalyst with high activity and stability for Fischer-Tropsch synthesis. ChemCatChem 2012, 4, 265-272. [CrossRef]

39. Minieri, L.; Esposito, S.; Russo, V.; Bonelli, B.; Di Serio, M.; Silvestri, B.; Vergara, A.; Aronne, A. A sol-gel ruthenium-niobium-silicon mixed-oxide bifunctional catalyst for the hydrogenation of levulinic acid in the aqueous phase. ChemCatChem 2017, 9, 1476-1486. [CrossRef]

40. Esposito, S.; Silvestri, B.; Russo, V.; Bonelli, B.; Manzoli, M.; Deorsola, F.A.; Vergara, A.; Aronne, A.; Di Serio, M. Self-activating catalyst for glucose hydrogenation in the aqueous phase under mild conditions. ACS Catal. 2019, 9, 3426-3436. [CrossRef]

41. Yang, H.; Zhang, L.; Zhong, L.; Yang, Q.; Li, C. Enhanced cooperative activation effect in the hydrolytic kinetic resolution of epoxides on [co(salen)] catalysts confined in nanocages. Angew. Chem. Int. Ed. 2007, 46, 6861-6865. [CrossRef] [PubMed]

42. Yang, H.; Ma, Z.C.; Wang, Y.K.; Wang, Y.W.; Fang, L. Hoveyda-Grubbs catalyst confined in the nanocages of SBA-1: Enhanced recyclability for olefinmetathesis. Chem. Commun. 2010, 46, 8659-8661. [CrossRef] [PubMed]

43. Deka, J.R.; Kao, H.M.; Huang, S.Y.; Chang, W.; Ting, C.C.; Rath, P.C.; Chen, C.S. Ethane-bridged periodic mesoporous organosilicas functionalized with high loadings of carboxylic acid groups: Synthesis, bifunctionalization, and fabrication of metal nanoparticles. Chem. Eur. J. 2014, 20, 894-903. [CrossRef]

44. Zhu, H.; Lee, B.; Dai, S.; Overbury, S.H. Coassembly synthesis of ordered mesoporous silica materials containing Au nanoparticles. Langmuir 2003, 19, 3974-3980. [CrossRef]

45. Wu, P.; Bai, P.; Yan, Z.; Zhao, G.X.S. Gold nanoparticles supported on mesoporous silica: Origin of high activity and role of Au NPs in selective oxidation of cyclohexane. Sci. Rep. 2016, 6, 18817. [CrossRef] 
46. Du, C.; Ao, Q.; Cao, N.; Yang, L.; Luo, W.; Cheng, G. Facile synthesis of monodisperse ruthenium nanoparticles supported on graphene for hydrogen generation from hydrolysis of ammonia borane. Int. J. Hydrogen Energy 2015, 40, 6180-6187. [CrossRef]

47. Zhang, Y.; Jiang, H.; Li, G.; Zhang, M. Controlled synthesis of highly dispersed and nanosized Ru catalysts supported on carbonaceous materials via supercritical fluid deposition. RSC Adv. 2016, 6, 16851-16858. [CrossRef]

48. Chandra, M.; Xu, Q. A high-performance hydrogen generation system: Transition metal-catalyzed dissociation and hydrolysis of ammonia-borane. J. Power Sources 2006, 156, 190-194. [CrossRef]

49. Yao, Q.L.; Shi, W.M.; Feng, G.; Lu, Z.H.; Zhang, X.L.; Tao, D.J.; Kong, D.J.; Chen, X.S. Ultrafine Ru nanoparticles embedded in $\mathrm{SiO}_{2}$ nanospheres: Highly efficient catalysts for hydrolytic dehydrogenation of ammonia borane. J. Power Sources 2014, 257, 293-299. [CrossRef]

50. Yao, Q.; Lu, Z.-H.; Yang, K.; Chen, X.; Zhu, M. Ruthenium nanoparticles confined in SBA-15 as highly efficient catalyst for hydrolytic dehydrogenation of ammonia borane and hydrazine borane. Sci. Rep. 2015, 5, 15186-15196. [CrossRef]

51. Cui, Z.; Guo, Y.; Feng, Z.; Xu, D.; Ma, J. Ruthenium nanoparticles supported on nitrogen-doped porous carbon as a highly efficient catalyst for hydrogen evolution from ammonia borane. New J. Chem. 2019, 43, 4377-4384. [CrossRef]

52. Tonbul, Y.; Akbayrak, S.; Özkar, S. Nanozirconia supported ruthenium (0) nanoparticles: Highly active and reusable catalyst in hydrolytic dehydrogenation of ammonia borane. J. Coll. Int. Sci. 2018, 513, 287-294. [CrossRef] [PubMed]

53. Taşçı, E.; Akbayrak, S.; Özkar, S. Ruthenium (0) nanoparticles supported on silica coated $\mathrm{Fe}_{3} \mathrm{O}_{4}$ as magnetically separable catalysts for hydrolytic dehydrogenation of ammonia borane. Int. J. Hydrogen Energy 2018, 43, 15124-15134. [CrossRef]

54. Chandra, M.; Xu, Q. Room temperature hydrogen generation from aqueous ammonia-borane using noble metal nano-clusters as highly active catalysts. J. Power Sources 2007, 168, 135-142. [CrossRef]

55. Xu, J.; Liu, W.; Yu, Y.; Du, J.; Li, N.; Xu, L. Synthesis of mono-dispersed mesoporous SBA-1 nanoparticles with tunable pore size and their application in lysozyme immobilization. RSC Adv. 2014, 4, 37470-37478. [CrossRef]

56. Zhang, J.; Chen, C.; Yan, W.; Duan, F.; Zhang, B.; Gao, Z.; Qin, Y. Ni nanoparticles supported on CNTs with excellent activity produced by atomic layer deposition for hydrogen generation from the hydrolysis of ammonia borane. Catal. Sci. Technol. 2016, 6, 2112-2119. [CrossRef]

(C) 2020 by the authors. Licensee MDPI, Basel, Switzerland. This article is an open access article distributed under the terms and conditions of the Creative Commons Attribution (CC BY) license (http://creativecommons.org/licenses/by/4.0/). 